Available online on 15.01.2021 at http://jddtonline.info
O 2011-21, publisher and licensee JDDT, This is an Open Access article which permits
unrestricted non-commercial use(CC By-NC), provided the original work is properly cited
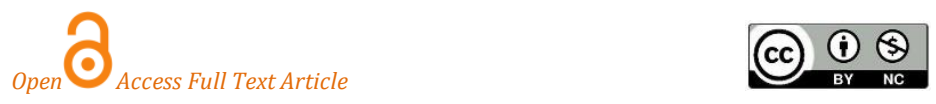

Research Article

\title{
Formulation and Evaluation of Orodispersible Tablet of Fluvastatin Sodium
}

\author{
Pooja Kanathe1, Ruchi Jain ${ }^{1}$, Nilesh Jain²* and Surendra Kumar Jain ${ }^{1}$ \\ ${ }^{1}$ Sagar Institute of Research \& Technology-Pharmacy, Ayodhya Bypass Road, Bhopal, M.P. India - 462041 \\ ${ }^{2 *}$ Sagar Institute of Research Technology \& Science-Pharmacy, Near ISRO, Bhopal, M.P. India - 462041
}

Article Info:
Article History:
Received 08 Nov 2020;
Review Completed 22 Dec 2020
Accepted 29 Dec 2020;
Available online 15 Jan 2021

Cite this article as:

Kanathe P, Jain R, Jain N, Jain SK, Formulation and Evaluation of Orodispersible Tablet of

Fluvastatin Sodium, Journal of Drug Delivery and Therapeutics. 2021; 11(1):42-47

DOI: http://dx.doi.org/10.22270/jddt.v11i1.4498

*Address for Correspondence:

Nilesh Jain, Professor, Sagar Institute of Research Technology \& Science-Pharmacy, Ayodhya Bypass Road, Bhopal - 462041

\section{Abstract}

The purpose of this research work is to formulate and evaluate the Orodispersible tablet of Fluvastatin Sodium to enhance the bioavailability and effectiveness of the drug. The objectives of the drug work were to formulate and evaluate Orodispersible tablets of Fluvastatin Sodium, having adequate mechanical strength, rapid disintegration, and fast action. Precompression parameters like angle of repose, bulk density, tapped density, compressibility index \& post-compression parameters like wetting time, water absorption ratio, in-vitro disintegration, and in-vitro dispersion time were studied. The hardness, friability, and drug content of all the formulations were found to be within the limits. The best formulation PK09 has shown good disintegration time, dissolution time, and dispersion time. The optimized formulation of batch PK9 gave the best in-vitro release of $99.60 \%$ in $3 \mathrm{~min}$ in phosphate buffer $\mathrm{pH}$ 6.8. The release of the drug followed the matrix diffusion mechanism as compared to the commercial formulation. Formulation PK9 gives quick disintegration and better drug release. Hence it can be concluded that the formulation of PK9 is stable and effective for quick action and it is an alternative to the conventional tablets.

Keywords: Orodispersible Tablets, Fluvastatin Sodium, Fast dissolving/disintegrating tablets, GIT, bioavailability, first-pass metabolism, superdisintegrants

\section{INTRODUCTION}

Orodispersible tablets are solid unit dosage forms like conventional tablets but are composed of super disintegrants, which help them to dissolve the tablets within a minute in the mouth in the presence of saliva without any difficulty of swallowing1. It offers several advantages concerning its stability, administration without water, accurate dosing, easy manufacturing, small packaging size, and handling. Its ease of administration in the population especially for pediatric, geriatric, or any mentally retarded persons makes it a very popular dosage form ${ }^{2,3}$. Due to the presence of superdisintegrants, it gets dissolved quickly, resulting in rapid absorption of drugs which in turn provides rapid onset of action. Since the absorption taking place directly from the mouth, so, the bioavailability of the drug increases. Drugs present in orodispersible tablets are also not suffering from first-pass metabolism. This type of drug delivery is becoming popular day by day due to its numerous advantages. ${ }^{4}$

These dosage forms are a preferable alternative for the oral medication in improving the quality of life and patient acceptability. The fast-dissolving property of the tablet is attributable to a quick ingress of water into the tablet matrix resulting in its rapid disintegration ${ }^{5-8}$. Hence, the basic approaches to developing ODTs involve maximizing the porous structure of the tablet matrix, incorporating the appropriate disintegrating agent, and using highly water- soluble excipients in the formulation. Various methods have been reported for the preparation of ODTs which include tablet molding, spray drying, sublimation, lyophilization, solid dispersion, the addition of disintegrants. ${ }^{9-12}$

Fluvastatin is an antilipemic agent that competitively inhibits hydroxymethylglutaryl-coenzyme A (HMG-CoA) reductase. HMG-CoA reductase catalyzes the conversion of HMG-CoA to mevalonic acid, the rate-limiting step in cholesterol biosynthesis. Fluvastatin belongs to a class of medications called statins and is used to reduce plasma cholesterol levels and prevent cardiovascular disease. Fluvastatin is a racemate comprising equimolar amounts of $(3 R, 5 S)$ - and (3S,5R)fluvastatin. Fluvastatin sodium is rapidly absorbed orally its oral bioavailability is $90 \%$ and the half-life is $3 \mathrm{hrs}$. it is rapidly and almost completely absorbed (>90\%) but undergoes extensive first-pass metabolism. Bioavailability is $24 \%$ (range $9-50 \%$ ) when a $10 \mathrm{mg}$ dose is given 13,14

In the present study, fluvastatin was selected as a model compound to develop an acceptable ODT formulation of this drug. The objective of the present study is to develop orodispersible tablets of fluvastatin using different types of super disintegrants like crospovidone (polyplasdone), croscarmellose sodium (Ac-Di-Sol), and sodium starch glycolate (explotab) to enhance the disintegration and dissolution of fluvastatin to improve the bioavailability of the drug and avoid the first pass metabolism. 


\section{MATERIALS AND METHODS}

\section{Materials}

Fluvastatin sodium was a gift from Hetero Labs Ltd., Hyderabad. Sodium Starch Glycolate, Crospovidone obtained from BASF Ltd., Pharmaco, Crosscarmellose Sodium purchased from Ascot Pharma Ltd., Microcrystalline Cellulose, Aspartame, Magnesium Stearate, Talc, Aerosil were purchased from SD fine chemicals, Mumbai, All the chemicals and solvents used in this study are of analytical grade.

\section{Apparatus}

UV-VIS Spectrophotometer (Shimadzu 1700, Shimadzu Corporation, Japan), Digital Balance, CX 400, Citizan. Melting Point Apparatus, Scientific International SI-934, Delhi.

Digital pH Meter, Equip-Tronics, Model EQ 610. FTIR Spectrophotometer, Alpha Bruker

Tablet Compression Machine, Cadmach Machinery co. Pvt. Ltd., Ahmadabad. Roche Friabilator, Scientific International, New Delhi. Tablet Hardness Tester, Monsanto Hardness Tester, Magumps, Bombay. Disintegration Apparatus, ED-2L Electrolab, Mumbai. Dissolution Test Apparatus II, USPXXIII, (TDT-08L) Plus, Electrolab, India were used for the study.

Formulation of Fluvastatin orodispersible tablets
The best type of superdisintegrants is incorporated in the formulation of ODTs like, Sodium starch glycolate, Crospovidone, Cross carmellose sodium. Before the tablet formulation, the superdisintegrants were screened out and taken into a formulation with other excipients for compression by the direct compression method.

In this work, the direct compression method with aid of superdisintegrants was attempted for the formulation development of orodispersible tablets of fluvastatin Sodium. The superdisintegrants like Sodium starch glycolate, Crospovidone, Cross carmellose sodium were taken for the formulation development. The fluvastatin Sodium tablets are available in $20 \mathrm{mg}$ to $80 \mathrm{mg}$ doses in the market. The dose of $20 \mathrm{mg}$ is selected for the present study.

Various superdisintegrants in different concentrations $(2.6 \%, 4 \%$, and $5.3 \%)$ were used to get tablets with good physical properties. Ingredients like Microcrystalline cellulose and mannitol as directly compressible diluents, magnesium stearate and talc as a lubricant, aerosil as flow promoter, aspartame as a sweetening agent, and pineapple flavor enhance the palatability. And Sodium Starch Glycolate (Carboxtmethyl Starch), Crospovidone (Polyplasdone XL), and Cross Carmellose Sodium (Ac- Di-Sol) were taken in different concentrations such as $2.6 \%, 4 \%$, and $5.3 \%$. The formulation design of orodispersible tablets of fluvastatin Sodium is shown in Table 1.

Table 1: Composition of different formulas

\begin{tabular}{|c|c|c|c|c|c|c|c|c|c|c|}
\hline Sr. No. & Ingredients (mg) & PK1 & PK 2 & PK 3 & PK 4 & PK 5 & PK 6 & PK 7 & PK 8 & PK 9 \\
\hline 1. & Fluvastatin Sodium & 20 & 20 & 20 & 20 & 20 & 20 & 20 & 20 & 20 \\
\hline 2. & Sodium starch glycolate & 4 & 6 & 8 & - & - & - & - & - & - \\
\hline 3. & Crospovidone & - & - & - & 4 & 6 & 8 & - & - & - \\
\hline 4. & Cross carmellose sodium & - & - & - & - & - & - & 4 & 6 & 8 \\
\hline 5. & $\begin{array}{c}\text { Microcrystalline } \\
\text { cellulose }\end{array}$ & 50 & 50 & 50 & 50 & 50 & 50 & 50 & 50 & 50 \\
\hline 6. & Aspartame & 6 & 6 & 6 & 6 & 6 & 6 & 6 & 6 & 6 \\
\hline 7. & Magnesium stearate & 1.5 & 1.5 & 1.5 & 1.5 & 1.5 & 1.5 & 1.5 & 1.5 & 1.5 \\
\hline 8. & Talc & 1 & 1 & 1 & 1 & 1 & 1 & 1 & 1 & 1 \\
\hline 9. & Aerosil & 0.5 & 0.5 & 0.5 & 0.5 & 0.5 & 0.5 & 0.5 & 0.5 & 0.5 \\
\hline 10 & Pineapple flavour & 1 & 1 & 1 & 1 & 1 & 1 & 1 & 1 & 1 \\
\hline 11 & Mannitol & 76 & 74 & 72 & 76 & 74 & 72 & 76 & 74 & 72 \\
\hline & Total & 160 & 160 & 160 & 160 & 160 & 160 & 160 & 160 & 160 \\
\hline
\end{tabular}

\section{Evaluation of the prepared formulas}

\section{Wetting time and water absorption ratio}

The wetting time of the tablet was measured by placing five circular tissue papers $(10 \mathrm{~cm}$ in diameter $)$ in a Petri dish of $10 \mathrm{~cm}$ diameter. Artificial saliva $(10 \mathrm{ml})$ (Table 2) containing methylene blue $(0.1 \% \mathrm{w} / \mathrm{v})$ was added to the Petri dish. A tablet was carefully placed on the surface of tissue paper, and the time required for the dye to reach the upper surface of the tablet was recorded as wetting time. Measurements were carried out in triplicate. Water absorption ratio was calculated using the following 15,16 .

Water absorption ratio $=(\mathrm{Wa}-\mathrm{Wb}) / \mathrm{Wb}$
Where $\mathrm{Wb}=$ weight of tablet before absorption of water, and $\mathrm{Wa}=$ weight of tablet after absorption of water.

Table 2: Composition of artificial saliva

\begin{tabular}{|l|l|}
\hline Materials & Amount (gm/L) \\
\hline Sodium chloride $(\mathrm{NaCl})$ & $\mathbf{0 . 4}$ \\
\hline Potassium chloride $(\mathrm{KCl})$ & $\mathbf{0 . 4}$ \\
\hline Calcium chloride(CaCl2.2H2O) & $\mathbf{0 . 8}$ \\
\hline $\begin{array}{l}\text { Sodium di hydrogen phosphate } \\
\text { (NaH2PO4.2H2O) }\end{array}$ & $\mathbf{0 . 7 8}$ \\
\hline Sodium sulfide (NaS.9H2O) & $\mathbf{0 . 0 5}$ \\
\hline Urea & $\mathbf{1}$ \\
\hline
\end{tabular}




\section{Content uniformity}

The content uniformity of the prepared formulas orodispersible tablets was performed by taking ten tablets and assayed individually. The requirement for this test is met if the amount of ingredient in each of the ten tablets lies within the range of $95 \%-102 \%$.

\section{Hardness}

Tablets require a certain amount of strength or hardness and resistance to Friability to with stand mechanical shocks. The hardness of tablet was measured by Monsanto hardness tester and results were expressed in $\mathrm{Kg} / \mathrm{cm}^{2}$. 17, 18

\section{Friability}

The friability of tablets was determined using Roche friabilator. It is expressed in percentage (\%). Ten tables were initially weighed (W initial) and transferred into friabilator. The friabilator was operated at $25 \mathrm{rpm}$ for 4 minutes or run up to 100 revolutions. The tablets were weighed again ( $\mathrm{W}$ final).

The percentage friability was then calculated using the following equation.

\section{F = Initial - Final $x$ 100/ Initial}

$\%$ Friability of tablets less than $1 \%$ are considered acceptable 19 .

\section{In vivo disintegration test}

Three human volunteers were involved in the determination of the disintegration time for each tablet formula; the time required for complete disintegration of the tablet when placed on the tongue was determined by tactile feedback using a stop watch ${ }^{20}$.

\section{In-vitro disintegration test}

The in-vitro disintegration time was determined using the disintegration test apparatus. A tablet was placed in each of the six tubes of the apparatus and one disc was added to each tube. The time in seconds taken for complete disintegration of the tablet with no palatable mass remaining in the apparatus was measured in seconds. The disintegration tests were done for the prepared orodispersible tablets using the USP disintegration apparatus, the basket rack assembly containing six openended tubes and 10- mesh screen on the bottom was used, and the six tubes are filled with artificial saliva instead of water, to simulate the in vivo environment as much as possible.

\section{In vitro dissolution studies}

In-vitro dissolution studies for orodispersible tablets of fluvastatin Sodium were carried out using USP apparatus type II at $50 \mathrm{rpm}$. The dissolution medium used was phosphate buffer $\mathrm{pH} 6.8(900 \mathrm{ml})$ maintained at $37 \pm 0.5^{\circ} \mathrm{C} . .^{21}$

Aliquots of dissolution media were withdrawn $(10 \mathrm{ml})$ at different intervals and the content of fluvastatin Sodium was measured by determining absorbance at $304 \mathrm{~nm} .10 \mathrm{ml}$ aliquot was withdrawn at the $0 \mathrm{~min}, 1 \mathrm{~min}, 2 \mathrm{~min}, 3 \mathrm{~min}$ ....to be continued at the $1 \mathrm{~min}$ intervals and filter by whatmann filter paper. And analyzed at $273 \mathrm{~nm}$ usingvisible spectrophotometer.

\section{Calibration curve of fluvastatin sodium in phosphate buffer pH 6.8:}

$50 \mu \mathrm{g} / \mathrm{ml}$ solution of fluvastatin sodium was prepared in phosphate buffer pH 6.8 and was subjected to scanning under UV visible spectrophotometer, between the range 200-400nm. The standard calibration curve of fluvastatin sodium was prepared by using phosphate buffer $\mathrm{pH} 6.8$ as a solvent. A standard calibration curve was obtained by plotting Absorbance Vs. Concentration.

\section{RESULTS AND DISCUSSION}

The direct compression method is the easiest way to manufacture tablets. In recent times, this technique has been applied to produce fast dissolving tablets because of the availability of improved tablet excipients, especially tablet disintegrants. Nine formulations were prepared by using $2.6 \%, 4 \%, 5.3 \%$ concentration of super disintegration of superdisintegrants sodium starch glycolate, crospovidone, and croscarmellose sodium.

\section{Determination of $\lambda$ max of Fluvastatin}

The UV scans of Fluvastatin in phosphate buffer (pH 6.8) showed peak, fig. 1 with $\lambda_{\max }$ at $304 \mathrm{~nm}$. (Figure 1)

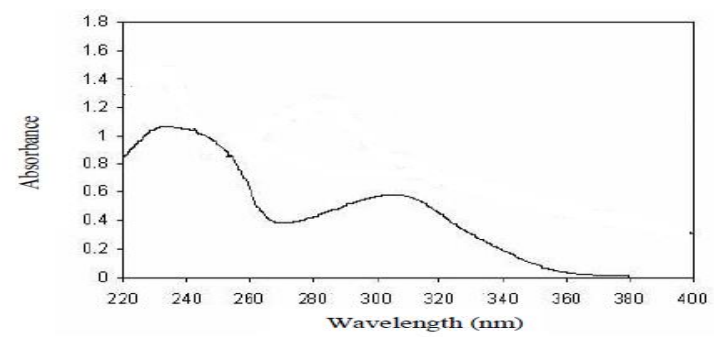

Figure 1: UV Spectrum of fluvastatin sodium in phosphate buffer pH 6.8

\section{Determination of calibration curve of Fluvastatin}

The standard calibration curve of fluvastatin sodium was prepared by using phosphate buffer $\mathrm{pH} 6.8$ as solvent. Standard calibration curve was obtained by plotting Absorbance Vs. Concentration. Table 8.4 shows the absorbance values of fluvastatin sodium. The standard curve is shown in figure 8.9, the standard calibration curve shows the correlation coefficient of 0.9998 . The curve was found to be linear in the concentration range of $5-25 \mu \mathrm{g} / \mathrm{ml}$ at 304.0 $\mathrm{nm}$. Thus, the standard curve followed the Beer-Lamberts Law, and the result is shown in Table 3 and Figure 2.

Table 3: Absorbance values for standard calibration curve of fluvastatin sodium in phosphate buffer pH 6.8

\begin{tabular}{|c|c|c|}
\hline Sr. No. & Concentration $(\boldsymbol{\mu g} / \mathbf{m l})$ & Absorbance \\
\hline 1 & $\mathbf{0}$ & $\mathbf{0}$ \\
\hline 2 & $\mathbf{5}$ & $\mathbf{0 . 2 8 1}$ \\
\hline 3 & $\mathbf{1 0}$ & $\mathbf{0 . 5 6 8}$ \\
\hline 4 & $\mathbf{1 5}$ & $\mathbf{0 . 7 4 8}$ \\
\hline 5 & $\mathbf{2 0}$ & $\mathbf{0 . 9 1 4}$ \\
\hline 6 & $\mathbf{1 2 5}$ & $\mathbf{1 . 2 0 8}$ \\
\hline
\end{tabular}

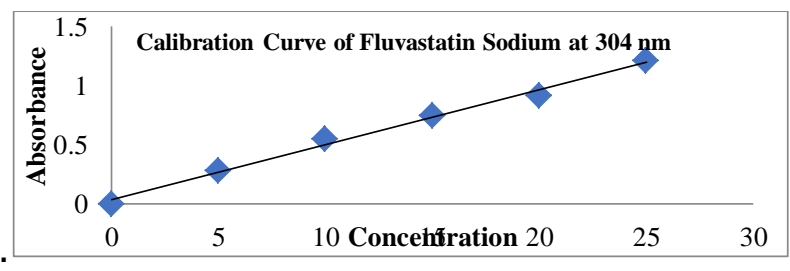

Figure 2: Standard calibration curve of Fluvastatin Sodium in pH 6.8 buffer

\section{Pre Compression Parameters:}

Results of pre-compression parameters evaluated were within limits and indicated good free-flowing property which is described in table 4. 
Table 4: Result of Pre Compression Parameter

\begin{tabular}{|c|c|c|c|c|c|}
\hline Batch code & $\begin{array}{c}\text { Angle of repose } \\
\mathbf{( \theta )}\end{array}$ & $\begin{array}{c}\text { Bulk density } \\
\text { (gm/cm3) }\end{array}$ & $\begin{array}{c}\text { Tapped density } \\
\text { (gm/cm3) }\end{array}$ & $\begin{array}{c}\text { Compressibility } \\
\text { Index (\%) }\end{array}$ & Hausner ratio \\
\hline PK1 & $30.61 \pm 0.21$ & $0.49 \pm 0.14$ & $0.611 \pm 0.14$ & $17.76 \pm 0.15$ & $1.216 \pm 0.22$ \\
\hline PK2 & $32.12 \pm 0.33$ & $0.510 \pm 0.36$ & $0.615 \pm 0.53$ & $18.04 \pm 0.16$ & $1.225 \pm 0.14$ \\
\hline PK 3 & $31.60 \pm 0.45$ & $0.5 \pm 0.47$ & $0.615 \pm 0.53$ & $20.20 \pm 0.63$ & $1.25 \pm 039$ \\
\hline PK 4 & $29.60 \pm 0.69$ & $0.5 \pm 0.56$ & $0.606 \pm 0.12$ & $17.49 \pm 0.69$ & $1.212 \pm 0.82$ \\
\hline PK 5 & $32.20 \pm 0.47$ & $0.508 \pm 0.14$ & $0.617 \pm 0.34$ & $17.66 \pm 0.48$ & $1.214 \pm 0.71$ \\
\hline PK 6 & $31.36 \pm 0.97$ & $0.518 \pm 0.89$ & $0.60 \pm 0.19$ & $14.58 \pm 0.67$ & $1.171 \pm 0.93$ \\
\hline PK 7 & $31.16 \pm 0.34$ & $0.518 \pm 0.24$ & $0.611 \pm 0.11$ & $16.58 \pm 0.11$ & $1.198 \pm 0.52$ \\
\hline PK 8 & $26.30 \pm 0.92$ & $0.519 \pm 0.4$ & $0.618 \pm 0.21$ & $17.35 \pm 0.23$ & $1.210 \pm 0.41$ \\
\hline PK 9 & $28.50 \pm 0.42$ & $0.520 \pm 0.19$ & $0.617 \pm 0.47$ & $16.08 \pm 0.14$ & $1.205 \pm 0.43$ \\
\hline
\end{tabular}

Mean \pm S.D $(n=5)$

\section{Post Compression Parameters:}

Tablets were evaluated for weight variation test, hardness, friability, wetting time, water absorption test, drug content, disintegration test. The results were illustrated in Table 5.
The hardness of all tables was between $1.9-2.2 \mathrm{Kg} / \mathrm{cm} 2$ while friability below $1 \%$ showed that all tablets have good mechanical strength. The disintegration time of all tablets was observed within a fraction of seconds.

Table 5 Post Compression Study of the Formulated Tablets

\begin{tabular}{|c|c|c|c|c|c|c|c|}
\hline Formulation & $\begin{array}{c}\text { Uniformity of } \\
\text { weight (mg) }\end{array}$ & $\begin{array}{c}\text { Thickness } \\
\mathbf{( m m )}\end{array}$ & $\begin{array}{c}\text { Hardness } \\
\mathbf{( k g / \mathbf { c m } ^ { 2 } )}\end{array}$ & $\mathbf{\%}$ Friability & $\begin{array}{c}\text { (\% w/w) } \\
\text { Drug } \\
\text { Content }\end{array}$ & $\begin{array}{c}\text { Disintegration } \\
\text { time (sec) }\end{array}$ & $\begin{array}{c}\text { Water } \\
\text { absorption } \\
\text { ratio } \pm \text { S.D }\end{array}$ \\
\hline Specified limit & $\mathbf{1 8 9 . 8 - \mathbf { 2 0 6 . 4 }}$ & $\mathbf{2 . 5} \mathbf{- 3 . 0}$ & $\mathbf{1 . 5} \mathbf{- 2 . 5}$ & $\begin{array}{c}\text { Not more than } \\
\mathbf{1 . 0 \%}\end{array}$ & $\mathbf{9 0 - 1 1 0 \%}$ & & \\
\hline PK1 & $160.85 \pm 0.6$ & $2.57 \pm 0.41$ & $1.98 \pm 0.16$ & $0.65 \pm 0.14$ & $98.96 \pm 0.33$ & 31 & $62.65 \pm 5.90$ \\
\hline PK2 & $159.25 \pm 0.4$ & $2.55 \pm 0.94$ & $1.98 \pm 0.82$ & $0.77 \pm 0.14$ & $99.02 \pm 0.64$ & 33 & $91.03 \pm 2.42$ \\
\hline PK 3 & $160.75 \pm 0.2$ & $2.55 \pm 0.57$ & $2.02 \pm 0.64$ & $0.58 \pm 0.22$ & $100.30 \pm 0.17$ & 32 & $67.76 \pm 6.04$ \\
\hline PK 4 & $158.20 \pm 0.3$ & $2.57 \pm 0.68$ & $1.95 \pm 0.91$ & $0.71 \pm 0.36$ & $99.16 \pm 0.91$ & 31 & $62.60 \pm 2.50$ \\
\hline PK 5 & $160.30 \pm 0.8$ & $2.56 \pm 0.59$ & $1.96 \pm 0.64$ & $0.84 \pm 0.85$ & $97.91 \pm 0.74$ & 32 & $67.56 \pm 5.40$ \\
\hline PK 6 & $161.48 \pm 0.4$ & $2.56 \pm 0.95$ & $2.0 \pm 0.54$ & $0.70 \pm 0.64$ & $98.95 \pm 0.245$ & 36 & $97.10 \pm 1.94$ \\
\hline PK 7 & $160.30 \pm 0.4$ & $2.57 \pm 0.64$ & $1.90 \pm 0.34$ & $0.55 \pm 0.94$ & $99.03 \pm 0.98$ & 28 & $83.81 \pm 5.77$ \\
\hline PK 8 & $159.60 \pm 0.2$ & $2.57 \pm 0.24$ & $2.20 \pm 0.21$ & $0.53 \pm 0.67$ & $99.3 \pm 0.12$ & 27 & $84.10 \pm 2.45$ \\
\hline PK 9 & $160.11 \pm 0.3$ & $2.59 \pm 0.37$ & $1.96 \pm 0.14$ & $0.78 \pm 0.27$ & $98.93 \pm 0.78$ & 26 & $61.65 \pm 5.90$ \\
\hline
\end{tabular}

Mean \pm S.D $(n=5)$

\section{In Vitro Dissolution Studies}

In vitro dissolution studies, as they are important for conventional tablets, are also important for ODTs. In vitro drug release studies of the optimized formulations were carried out at $\mathrm{pH}$ 6.8. The $\mathrm{pH} 6.8$ was selected to assess any pregastric absorption that may take place when some of the particles from the orodispersible formulation get lodged into the denture and gradually may get absorbed through buccal mucosa.

The Comparative analysis of each formulation was based on in vitro kinetic parameters, which elucidated the release profile. The in-vitro drug release of orodispersible tablets of fluvastatin sodium for all formulation is given in Table 6 . 
Table 6 Comparative in-vitro drug release profile of all batches

\begin{tabular}{|r|r|c|c|c|c|c|c|c|c|c|}
\hline \multicolumn{1}{|c|}{} & \multicolumn{9}{|c|}{ Percent drug release } \\
\hline $\begin{array}{r}\text { Sr. } \\
\text { No. }\end{array}$ & $\begin{array}{l}\text { Time } \\
\text { (MIN) }\end{array}$ & PK1 & PK2 & PK3 & PK4 & PK5 & PK6 & PK7 & PK8 & PK9 \\
\hline 1 & 0 & 00 & 00 & 00 & 00 & 00 & 00 & 00 & 00 & 00 \\
\hline 2 & 1 & 16.39 & 22.49 & 22.29 & 20.96 & 20.96 & 22.39 & 21.51 & 32.39 & 52.63 \\
\hline 3 & 2 & 28.62 & 39.32 & 49.62 & 32.15 & 32.15 & 39.62 & 42.70 & 53.58 & 72.63 \\
\hline 4 & 3 & 54.39 & 51.39 & 74.39 & 55.09 & 55.09 & 68.39 & 62.35 & 75.86 & 99.60 \\
\hline 5 & 4 & 65.53 & 77.56 & 92.50 & 77.59 & 77.59 & 77.5 & 97.15 & 98.97 & \\
\hline 6 & 5 & 78.36 & 91.65 & 97.79 & 85.35 & 88.62 & 92.36 & & & \\
\hline 7 & 6 & 95.35 & & & 91.35 & 98.96 & & & & \\
\hline 8 & 7 & & & & 99.25 & & & & & \\
\hline
\end{tabular}

From the above observation, we can conclude that as the concentration of sodium starch glycolate, crospovidone, and cross carmellose sodium increase the disintegration time also increase. But the superdisintegrant cross carmellose sodium gives the minimum disintegrating time as compare to sodium starch glycolate or crospovidone. In the batch of cross carmellose sodium gives minimum disintegrating time and drug release in 3 mins. at the concentration of $5.3 \%$ of cross carmellose sodium. And the batch of sodium starch glycolate and crospovidone (at the same conc. of superdisintegration i.e. 5.3\%) gives the more disintegration time.

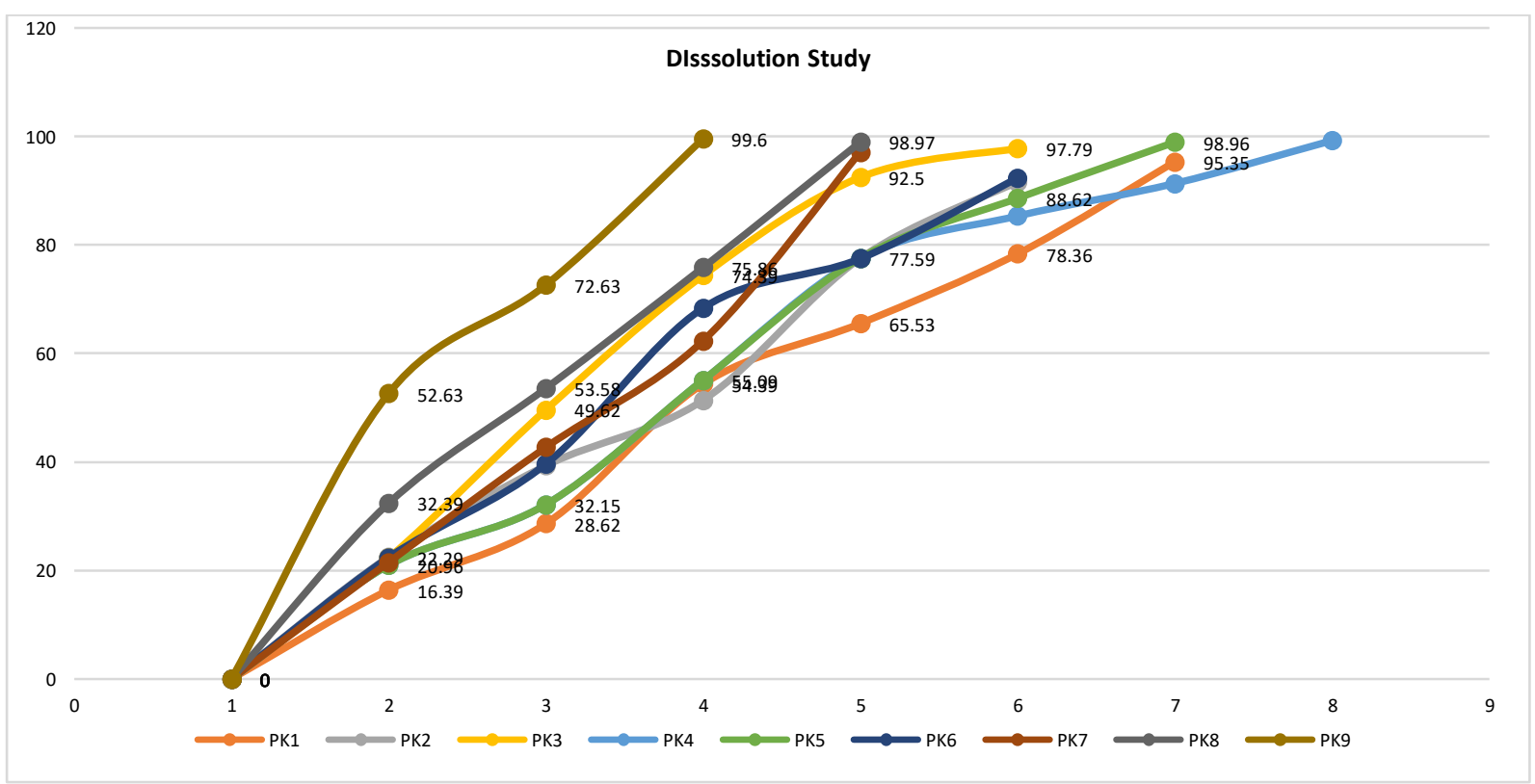

Figure 3: Comparative in vitro drug release profile of batches PK1 to PK9

\section{SUMMARY}

From the present study carried out on Fluvastatin Sodium orodispersible tablet using by direct compression method. The total weight of PK9 batch was $160 \mathrm{mg}$ contained Fluvastatin Sodium $-6.6 \%$, croscarmellose sodium-5.3\%, microcrystalline cellulose-33.3\%, aspartame-4\%, magnesium stearate- $1 \%$, talc- $0.6 \%$, aerosil- $0.3 \%$, pineapple flavor- $0.6 \%$, mannitol-48\%. The Prefromulation study gives the following information on optimizing batch Angle of Repose-280.50 Bulk density-0.520, Tapped density-0.627, Compressibility Index-16.08 good to flow, Hausner ratio-1.205. Post parameter evaluation of tablets Hardness-1.96, Friability0.788, Thickness-2.590, Weight variation-160.11 Dispersion time-29 sec, Water absorption ratio-61.65, Disintegration time-26 sec, Content uniformity-98.93\%, In- vitro drug release studies- in $3 \mathrm{~min}$. If the concentration of croscarmellose sodium increases it gives quickly the disintegration and dissolution were observed. So the results give information that Disintegration time in $26 \mathrm{sec}$ and dissolution in $3 \mathrm{~min}$. Croscarmellose sodium is the optimized batch on basis of disintegration time and in-vitro drug release. The optimized formulation of batch PK9 gave the best in-vitro release of $99.60 \%$ in $3 \mathrm{~min}$ in phosphate buffer $\mathrm{pH}$ 6.8. The release of the drug followed the matrix diffusion mechanism.

\section{CONCLUSION}

Our objective to cost-effective orodispersible tablet by direct compression quickly disperse in the oral cavity and it gives the fast release action for its antiemetic activity. Fast 
disintegration of tablets formulated in this investigation may be helpful in the administration of Fluvastatin Sodium in a palatable form without water during emesis. Formulation PK9 gives quick disintegration and better drug release. Hence it can be concluded that the formulation PK9 is stable and effective for quick action and it is an alternative to the conventional tablets.

\section{ACKNOWLEDGEMENT}

The authors are thankful to the Sagar Institute of Research \& Technology-Pharmacy- Bhopal, M.P for providing the necessary facilities to carry out the research work.

\section{REFERENCES}

1. Sutradhar KB, Akhter DT, Uddin R. Formulation and evaluation of taste masked oral dispersible tablets of domperidone using sublimation method. Int. J. Pharm. Pharm. Sci. 2012; 4(2):72732.

2. Basu BI, Bagadiya AB, Makwana S, Kapadiya MA. Design and evaluation of sublimed orodispersible tablets of Cetrizine $\mathrm{HCl}$ using superdisintegrant blends by direct compression. Int J Pharm Pharm Sci. 2011; 3:435-41.

3. Palkhede MB, Amrutkar SV, Erande KB. Formulation, optimization and evaluation of fast disintegrating tablet of mebeverine $\mathrm{HCl}$. International Journal of Pharmacy and Pharmaceutical Sciences. 2012; 4(4):121-5.

4. Dey P, Maiti S. Orodispersible tablets: A new trend in drug delivery. Journal of natural science, biology, and medicine. 2010; 1(1):2.

5. Furtado S, Deveswaran R, Bharath S, Basavaraj BV, Abraham S, Madhavan V. Development and characterization of orodispersible tablets of famotidine containing a subliming agent. Tropical journal of pharmaceutical research. 2008; $7(4): 1185-9$

6. Singh J, Singh R. Optimization and formulation of orodispersible tablets of meloxicam. Tropical Journal of Pharmaceutical Research. 2009; 8(2).

7. Abed KK, Hussein AA, Ghareeb MM, Abdulrasool AA. Formulation and optimization of orodispersible tablets of diazepam. Aaps Pharmscitech. 2010; 11(1):356-61.

8. Ghosh T, Ghosh A, Prasad D. A review on new generation orodispersible tablets and its future prospective. International journal of pharmacy and pharmaceutical sciences. 2011; 3(1):17.

9. World Medical Association. World Medical Association Declaration of Helsinki: ethical principles for medical research involving human subjects. Jama. 2013; 310(20):2191-4.

10. Kulkarni MS, Zeeshan A, Bhise KS, Somwanshi SV. Formulation and evaluation of orodispersible tablet of ornidazole. Int. J. Pharm. Stud. Res. 2010; 1:39-47.

11. Sreenivas SA, Dandagi PM, Gadad AP, Godbole AM, Hiremath SP, Mastiholimath VS, Bhagawati ST. Orodispersible tablets: Newfangled drug delivery system-A review. Indian Journal of Pharmaceutical Education. 2005; 39(4):177.

12. Radke RS, Jadhav JK, Chajeed MR. Formulation and evaluation of orodispersible tablets of baclofen. Int J Chem Tech Res. 2009; 1(3):517-21.

13. Rao U. Gastroretentive System of Fluvastatin Sodium by Using Natural Mucilage and Synthetic Polymer. International Journal of Drug Delivery Technology. 2014; 4(02):22-3.

14. Tse FL, Jaffe JM, Troendle A. Pharmacokinetics of fluvastatin after single and multiple doses in normal volunteers. The Journal of Clinical Pharmacology. 1992; 32(7):630-8.

15. Goyani M, Shah P, Vyas B, Shah D. Formulation and evaluation of orodispersible tablets of meclizine hydrochloride. International Research Journal of Pharmacy. 2012; 3:196-9.

16. Malik K, Arora G, Singh I. Ocimum sanctum seeds, a natural superdisintegrant: Formulation and evaluation of fast melt tablets of nimesulide. Polim Med. 2012; 42(1):49-59.

17. Pandurangan DK, Vuyyuru T, Kollipara D. Fast dissolving tabletsAn overview. International Journal of Research in Pharmaceutical Sciences. 2012; 3(2):348-55.

18. Gupta DK, Sharma RD, Gupta R, Tyagi S, Sharma KK, Choudhary A. Formulation and Evaluation of Orodispersible Tablets of Salbutamol Sulphate. International Journal of Pharmaceutical Sciences and Research. 2012; 3(8):2675.

19. Veeraveni R, Kamaeswara Rao CH, Shreedhar Nampalli GK, Krishna PC SP. Design and evaluation of orodispersible taste masked valdecoxib tablets. Journal of Chemical and Pharmaceutical Research. 2011; 3(4):882-92.

20. Ibrahim HK, El-Setouhy DA. Valsartan orodispersible tablets: formulation, in vitro/in vivo characterization. Aaps Pharmscitech. 2010; 11(1):189-96.

21. Abed KK, Hussein AA, Ghareeb MM, Abdulrasool AA Formulation and optimization of orodispersible tablets of diazepam. Aaps Pharmscitech. 2010; 11(1):356-61. 